\title{
EDITORIAL
}

\section{Working together to bring you a world class journal}

Lorna Davies

Sub-editor

In 2016 you will have periodically received the nine research articles that you now

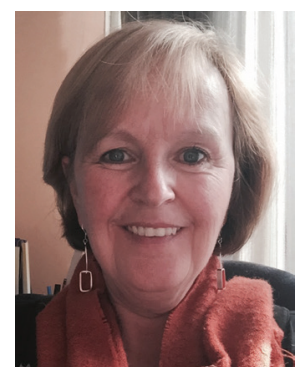

find included in Issue 52 of the New Zealand College of Midwives Journal. These articles have been brought to you as a result of ongoing activity on the part of the editorial board throughout the year. I am the most recent addition to the editorial team, having joined the group in the latter half of 2015. In the short period that I have been a sub-editor, I have seen the group work industriously from locations around New Zealand, and in some cases beyond, to produce an impressive and diverse body of maternity-related research generated by midwives and those within associated professions in Aotearoa/New Zealand. When I was asked to write the editorial for this collective edition, I thought about what I could contribute and what approach I should take. Should I write a clarion call for action style editorial or draw on reflection on practice. Eventually it occurred to me that in my role as newcomer I was in the privileged position of viewing the editorial team and processes through relatively fresh eyes. As a result, I felt motivated to write a piece that honours the work that the editors, sub-editors and support crew carry out behind the scenes of the Journal.

Our editorial board of two editors and four sub-editors meets online on a monthly basis using Skype, usually before our "day jobs" commence. The minutes and the agenda are distributed in advance so that we all have an idea of what will be discussed. The primary aim of the editorial board is to provide members with a series of robust New Zealand based research articles that contribute to the distinctive body of knowledge produced from those who work within, alongside or as observers of our unique maternity system.

When a paper is submitted to the Journal, it is considered by the board and an editor or sub-editor is appointed to direct the paper through a process that will ensure quality assurance. Support mechanisms that offer good support and constructive feedback for authors are used. This stage involves the arrangement of a doubleblind critique of the paper by two of our valued journal reviewers, who have been selected because of their midwifery knowledge and research expertise, which may be methodologically or content based. The paper then commutes back to the editor or sub-editor, who liaises with the author about the feedback, suggestions and recommendations of the peer reviewers, until the paper is accepted in principle. A robust proof-reading process follows, adding the finishing touches with regard to style and grammar etc.

The selection and editing of articles may seem to be an obvious part of the role of the board. However, the work of the group of editors and sub-editors goes far beyond that sphere of activity and I would like to share a number of activities that have been considered, discussed and sometimes implemented by the group recently. In the past twelve months the committee has researched the subject of creative commons, a form of licensing of materials that has an impact on copyright. The members have been working to ensure the Journal meets the Committee on Publication Ethics (COPE) best practice guidelines for Journal editors. This has involved ensuring transparent processes for authors and maintaining academic integrity. It has included the drawing up of a framework so that the Journal can be indexed with other databases (the Journal is currently indexed with Cinahl). Indexing more widely will support the dissemination of the Journal articles. One of our sub-editors has produced a PowerPoint presentation on "Writing for Publication". Others have been working on a journal index and updating the reflection tool. Yet more activity has involved organising the archiving of older versions of the Journal for online access, updating of reviewer guidelines and the task of finding new reviewers for research articles. During the NZCOM Biennial Conference in Auckland in August this year, the editors provided a workshop and made themselves available to discuss writing for publication for those who might be interested in taking the plunge and publishing.

There is a team of people involved in getting an article to publication, which includes Rhondda Davies (proofreading) and Hayley McMurtrie (layout) and I would like to make a special mention of Annie Oliver in the Christchurch Office for her administrative co-ordination of the Journal. I acknowledge that this brief account is just a snapshot but hopefully it will have given an insight and a greater sense of appreciation of the work that goes into bringing you the articles throughout the year and the collective edition of the Journal at the end of the year.

This year there has been a broad scope of articles in the collection, covering a whole range of aspects related to midwifery care and provision. The year commenced with an article on nutrition and healthy weight gain from Paterson et al., where the "teachable moment" was identified as a window of opportunity for health education and promotion. The two articles following were the culmination of findings from a study exploring the experience of new graduates in New Zealand and how best to support them. Susan Crowther throws down the gauntlet in the title of her study on remote rural midwifery care, imploring the need for improved remuneration for rural midwives. Jane Currie and Carrie Cornsweet Barber use a qualitative approach to help us to understand the experiences of women with medical conditions in pregnancy and how best to support them. Smoking cessation is explored in an evaluative study by Mentor, Pihema and Kira, who found that intercession at an early stage in pregnancy may make a difference. The article by Debra Betts and her co-researchers offers findings from a retrospective study that explored the benefit of acupuncture for women presenting with back or pelvic pain and found high levels of satisfaction. The team of researchers from AUT publish the third in their series on sustainable midwifery practice, focusing this time on reciprocity and generosity of spirit. The final article for the year by Carla Houkamau and her colleagues is an important piece of social commentary that strongly advocates that greater attention must be given to the impact of social and socio-economic factors if SUDI rates are to be reduced in Māori communities. We hope that you have enjoyed the articles brought to you this year and that you will continue to support the Journal by providing us with the articles of high quality that have become the hallmark of this Journal. 